\title{
REDUÇÃO DE CUSTO COM MATERIAIS DE DESGASTE DE PERFURAÇÃO*
}

\author{
Adelson Goncalves ${ }^{1}$ \\ Alisson Oliveira da Silva² \\ Itany Luzia da Silva ${ }^{3}$ \\ Joao Paulo Rodrigues de Souza ${ }^{4}$ \\ Nicodemos Gregório da Silva ${ }^{5}$ \\ Nilton Auxiliador Pereira Junior ${ }^{6}$
}

\section{Resumo}

No processo de extração mineral, a perfuração de rocha é uma atividade essencial. Por isso, a redução de custo com materiais de desgaste é sempre um desafio para todos no campo da mineração. A partir desse desafio, o grupo de melhoria contínua Perfuração desenvolveu um projeto que visa redução de custo com buchas guia de hastes para perfuratrizes de grande porte. A metodologia aplicada para elaboração do projeto foi o PDCA, onde foi desenvolvido um novo modelo de bucha que evita o descarte precoce da peça, otimizando a vida útil e consequentemente reduzindo o custo com materiais de desgaste de perfuração.

Palavras-chave: Mineração; Perfuração de rocha; Perfuratriz; Materiais de desgaste.

\section{REDUCING COST OF DRILLING WEAR MATERIALS}

\begin{abstract}
In the process of mining, rock drilling is an essential activity. Therefore, the cost reduction with wear materials is always a challenge for everyone in the mining field. From this challenge, the continuous improvement group Drilling developed a project aimed at reducing cost bushings guide rods for large drills. The methodology applied for the preparation of the project was the PDCA, where it was developed a new bushing model that prevents premature disposal of the part, optimizing the life and consequently reducing the cost of drilling wear materials.
\end{abstract}

Keywords: Rock drilling; Wear materials; Mining; Drill.

1 Adelson Gonçalves, Técnico de Mineração, Instrutor de Mina, Infraestrutura de Mina, Vale SA, Mariana, Minas Gerais, Brasil.

2 Alisson Oliveira da Silva, Engenheiro de Produção, Auxiliar de Produção, Infraestrutura de Mina, Vale SA, Mariana, Minas Gerais, Brasil.

3 Itany Luzia da Silva, Técnico em Segurança do Trabalho, Segurança e Saúde Ocupacional, Vale SA, Mariana, Minas Gerais, Brasil.

4 João Paulo Rodrigues de Souza, Ensino Médio Completo, Auxiliar de Produção, Infraestrutura de Mina, Vale SA, Mariana, Minas Gerais, Brasil.

5 Nicodemos Gregório da Silva, Ensino Médio Completo, Auxiliar de Produção, Infraestrutura de Mina, Vale SA, Mariana, Minas Gerais, Brasil.

6 Nilton Auxiliador Pereira Júnior, Técnico de Mineração, Técnico de Mina e Geologia II, Infraestrutura de Mina, Vale SA, Mariana, Minas Gerais, Brasil. 


\section{INTRODUÇÃO}

\subsection{Perfuratriz}

Uma perfuratriz ou equipamento de perfuração é uma máquina que realiza perfurações em solo ou rochas com o objetivo de produzir um furo ou poço de determinada profundidade.

Temos três tipos de perfuratriz: As de grande porte são a SKS (esteira) e 1190 (elétrica), sendo que, temos apenas duas perfuratrizes 1190 na América Latina e elas se encontram em Itabira/MG. As de médio porte - T4 apresentam uma particularidade, possuem duas cabines, sendo uma para perfuração e outra para locomoção. E a de pequeno porte - L8 usada para "fogo secundário" ou rapé.

\subsection{Processo de perfuração}

A perfuração da rocha dentro do campo do desmonte é a primeira operação a ser realizada e tem como finalidade abrir furos para alojar as cargas de explosivos e acessórios iniciadores para fazer o desmonte.

\subsection{A bucha guia dentro da perfuração}

A bucha guia tem por função direcionar e estabilizar a coluna de perfuração no momento em que ela está realizando os furos. Sem a bucha, a haste fica solta, colidindo com as bordas da mesa de perfuração, vindo a danificar a mesa e a haste.

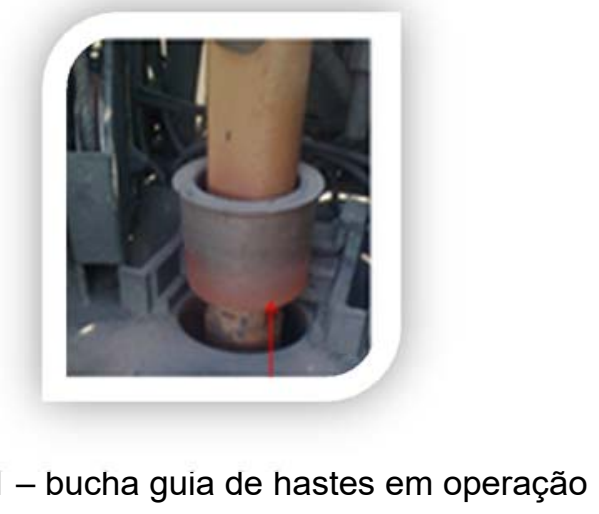

Preço unitário da bucha guia da haste:

2014: R\$ 23.000,00 / 2015: R\$ 53.871,69

Vida útil da bucha: 7.435 metros perfurados

Custo da bucha guia por metro perfurado:

$\mathrm{R} \$ 23.000,00$ (custo bucha guia) / 7.435 metros perfurados $=\mathrm{R} \$ 3,09$

Custo da bucha guia por metro perfurado em 2014:

$\mathrm{R} \$ 3,09$ (custo por metro perfurado) $\times 282.558,8$ Metros perfurados $=\mathrm{R} \$ 874.000,00$ O projeto tem como objetivo reduzir o custo por metro perfurado com bucha guia de haste de perfuratrizes de grande porte.

\section{MATERIAIS E MÉTODOS}

O método aplicado para a solução do problema foi o PDCA. 


\subsection{Seleção do problema}

O grupo realizou um brainstorming na área e levantou 15 problemas relacionados aos processos de desmonte, perfuração, despacho e geral.

Tabela 1 - Problemas elencados na gerencia

\begin{tabular}{|c|c|c|}
\hline \# & PROBLEMAS & PROCESSOS \\
\hline 1 & Baixa qualidade do desmonte no Complexo Mariana. & Desmonte \\
\hline 2 & Baixa utilização dos caminhōes graneleiros. & Desmonte \\
\hline 3 & Esforço físico intenso ao realizar transporte manual de cargas. & Desmonte \\
\hline 4 & Esforço físico intenso ao realizar tamponamento manual de furos. & Desmonte \\
\hline 5 & Baixa disponibilidade física das perfuratrizes. & Perfuração \\
\hline 6 & Custo elevado com materiais de desgaste de perfuração & Perfuração \\
\hline 7 & Quebra constante da coluna de perfuração durante a operação & Perfuração \\
\hline 8 & Baixa vida útil das ferramentas de perfuração & Perfuração \\
\hline 9 & Melhorar UF de perfuratriz (falta de operador / eqpto disponivel) & Perfuração \\
\hline 10 & Rever fluxo de apropriação de equipamentos e capacitar operadores & Despacho \\
\hline 11 & Equipar $100 \%$ dos equipamentos com kit de comunicação com despacho & Despacho \\
\hline 12 & Reduzir consumo de gasolina com Duster. & Geral \\
\hline 13 & Reduzir custo com hastes de perfuratriz & Perfuração \\
\hline 14 & Avaliar troca de rádios por "walk talk" no momento de detonação & Desmonte \\
\hline 15 & Reduzir custo com rádios dos "AEM" & Geral \\
\hline
\end{tabular}

Através do Gráfico de Pareto, o grupo estratificou os problemas por processo e verificou que a perfuração apresentava a maior incidência.

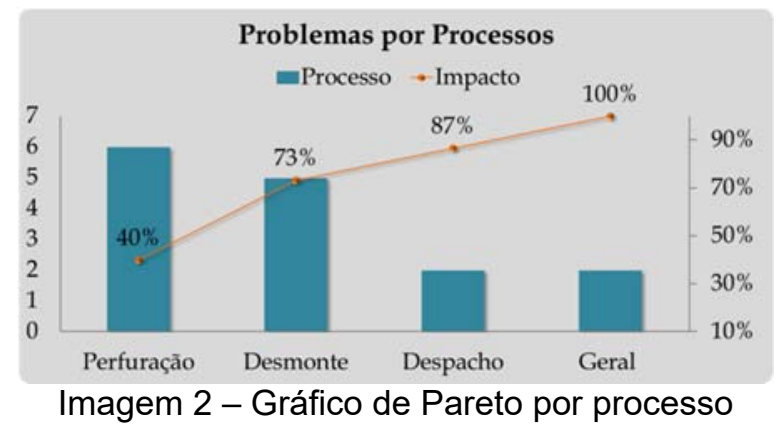

Em seguida os problemas do processo de perfuração foram classificados nas categorias "atendimento" e "custo", conforme gráfico seguinte.

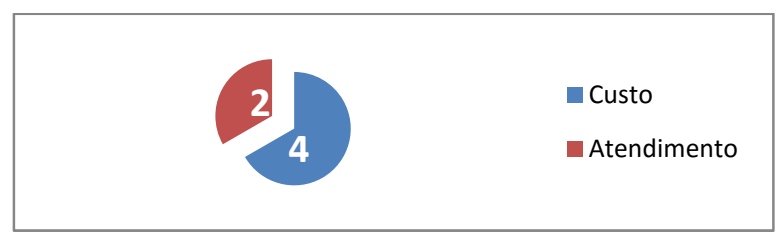

Imagem 3 - Gráfico de pizza por impacto

Identificamos que os problemas da categoria "custo" apresentavam maior incidência dentro do processo de perfuração.

Utilizando a matriz de priorização $\mathrm{RAB}$, avaliamos os critérios de rapidez, autonomia e benefício, onde definimos o foco de atuação do projeto, sendo este o custo elevado com materiais de desgaste de perfuração. 


\begin{tabular}{|c|c|c|c|c|c|}
\hline $\mathrm{N}^{\circ}$ & PROBLEMAS & RAPIDEZ & AUTONOMIA & BENEFICIO & TOTAL \\
\hline 1 & $\begin{array}{l}\text { Custo elevado com materiais de desgaste de } \\
\text { perfuração }\end{array}$ & 3 & 4 & 4 & 48 \\
\hline 2 & $\begin{array}{l}\text { Quebra constante da coluna de perfuração durante a } \\
\text { operação }\end{array}$ & 2 & 1 & 5 & 10 \\
\hline 3 & Baixa vida útil das ferramentas de perfuração & 2 & 2 & 5 & 20 \\
\hline 4 & Reduzir custo com hastes de perfuratriz & 2 & 3 & 5 & 30 \\
\hline
\end{tabular}

Através do gráfico de pareto detalhamos os gastos com consumo de todos os materiais de desgaste de perfuração no ano de 2014.

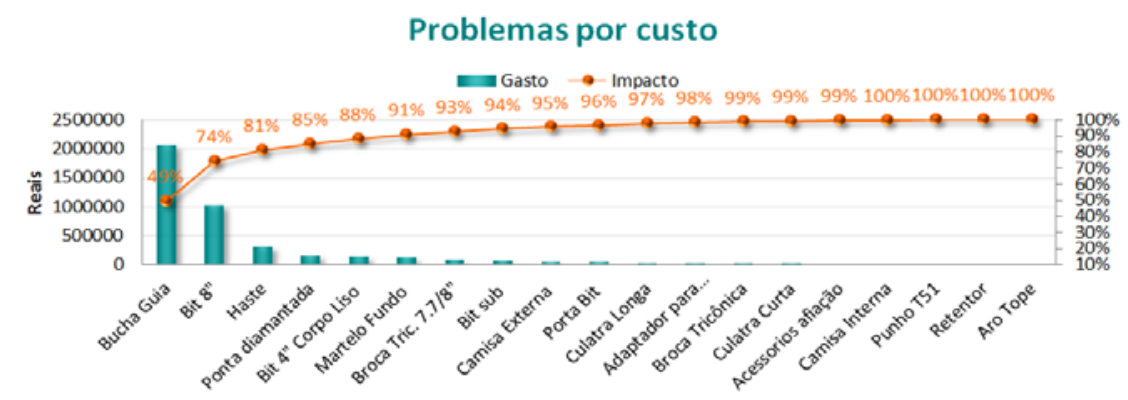

Imagem 4 - Gráfico de Pareto por custos por ferramenta

Evidenciamos que o maior gasto no ano de 2014 foi com aquisição de bucha guia da haste de perfuratriz de grande porte, sendo esse o nosso problema priorizado.

\subsection{Importâncias de solucionar o problema}

Para levantar todos os impactos relacionados à bucha guia da haste da perfuratriz de grande porte foi utilizada a ferramenta QCAMS.MA, onde seus impactos foram elencados conforme abaixo.

\subsubsection{Custo}

Em 2014 o valor unitário da bucha guia de haste era de $R \$ 23.000,00$ e a média de vida útil da bucha era de apenas 7.435 metros perfurados.

Para calcularmos o custo por metros perfurados, levantamos o valor unitário da peça e dividimos pela sua vida útil. Sendo assim o $\mathrm{CMP}=\mathrm{VLU} / \mathrm{VIU}$

Onde: CMP: Custo por metro perfurado; VLU: Valor unitário da peça; VIU: Vida útil.

Só em 2014 foram perfurados 282.558,8 metros com o custo (CMP) de R\$ 3,09 /metro perfurado utilizando a bucha guia de hastes, gerando um gasto total de $\mathrm{R} \$ 874.000,00$.

Devido à alta do dólar, o VLU subiu em $134 \%$ chegando ao valor de $R \$ 53.871,00$ o que causaria o aumento no CMP para $R \$ 7,24$.

Com isso, o gasto com bucha guia de haste em 2015 seria de $R \$ 2.047 .329,10$ representando $90 \%$ do gasto com materiais de desgaste de perfuração.

\subsubsection{Atendimento}

Tempo elevado para a troca da bucha guia nas perfuratrizes.

Tempo médio de 17 minutos. 
Tabela 3 - Lista de tempo médio de troca das buchas

\begin{tabular}{|c|c|c|c|}
\hline Troca & Tempo & PF & Data \\
\hline 1 & 17,00 & 1121 & $10 / 04 / 2014$ \\
\hline 2 & 21,00 & 1122 & $11 / 04 / 2014$ \\
\hline 3 & 32,00 & 1123 & $20 / 04 / 2014$ \\
\hline 4 & 13,00 & 0802 & $07 / 04 / 2014$ \\
\hline 5 & 25,00 & 1121 & $12 / 05 / 2014$ \\
\hline 6 & 18,00 & 1122 & $16 / 05 / 2014$ \\
\hline 7 & 18,00 & 1123 & $09 / 05 / 2014$ \\
\hline 8 & 12,00 & 0802 & $15 / 05 / 2014$ \\
\hline 9 & 11,00 & 1121 & $12 / 06 / 2014$ \\
\hline 10 & 17,00 & 1122 & $15 / 06 / 2014$ \\
\hline 11 & 16,50 & 1123 & $17 / 06 / 2014$ \\
\hline 12 & 16,00 & 0802 & $05 / 06 / 2014$ \\
\hline 13 & 13,00 & 1121 & $14 / 07 / 2014$ \\
\hline 14 & 11,00 & 1122 & $22 / 07 / 2014$ \\
\hline 15 & 15,00 & 1123 & $13 / 07 / 2014$ \\
\hline 15 & 15,00 & 0802 & $03 / 07 / 2014$ \\
\hline Média & 17,03 & & \\
\hline & & & \\
\hline
\end{tabular}

\subsubsection{Segurança}

Identificamos que havia excesso de esforço físico para a realização do transporte e troca da bucha guia de haste devido ao seu peso, a bucha pesa em torno $54 \mathrm{~kg}$. De acordo com a Norma Regulamentadora Federal 17/78 (NR17) que orienta quanto às condições ergonômicas no trabalho, cada pessoa deve transportar no máximo $23 \mathrm{~kg}$ por vez, gerando assim um desconforto físico e moral para os executantes da atividade. Além dos riscos ergonômicos existia também risco de prensamento e esmagamento dos membros superiores em todas as atividades de troca de bits, brocas, martelos e hastes devido ao peso da bucha guia.
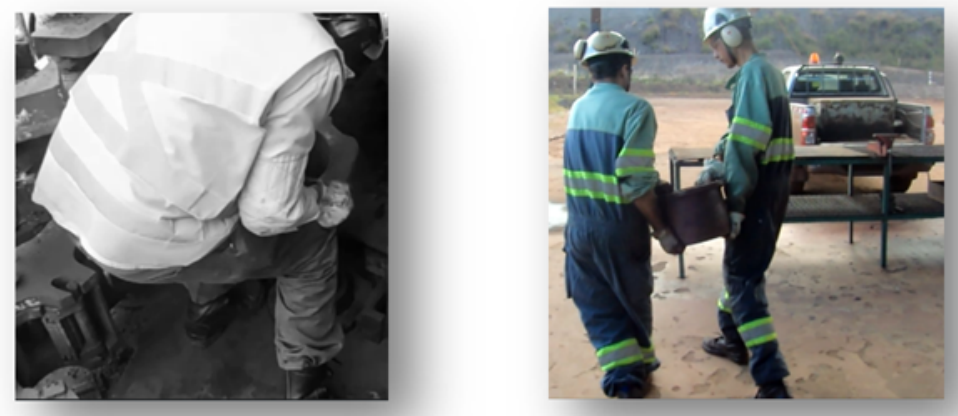

Imagem 5 - Operador realizando troca da bucha

Imagem $\sigma$ - Auxiliares realizando transporte da bucha

\subsubsection{Meio ambiente}

Devido à estrutura da bucha, toda vez que a mesma é descartada, é gerado $54 \mathrm{~kg}$ de sucata ferrosa. Só em 2014 foram descartadas 38 peças, gerando um total de $2052 \mathrm{~kg}$ de sucatas. 


\subsection{Meta}
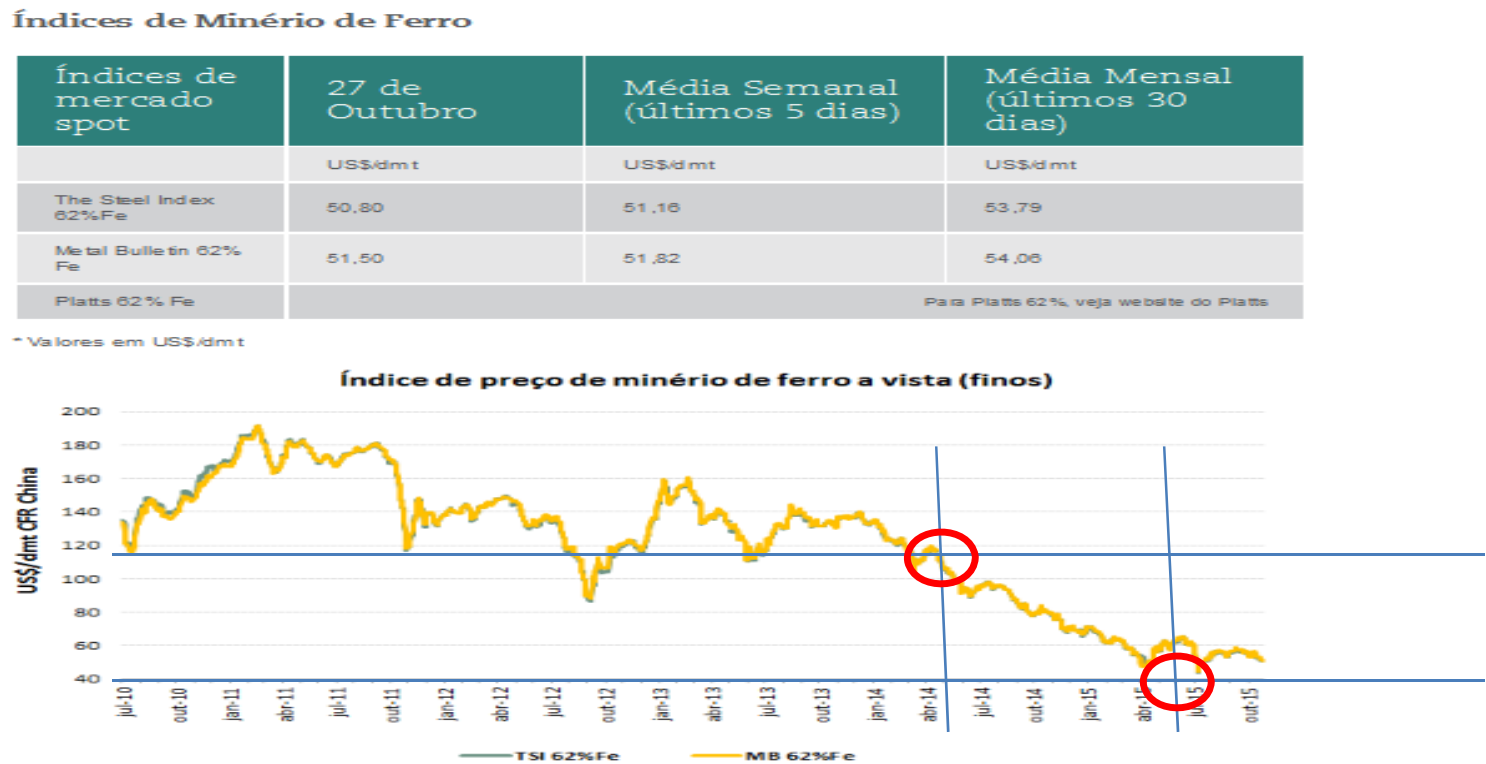

Imagem 7 - Gráfico com índice do preço do minério de ferro

Com o cenário atual de queda no preço do minério de ferro, a meta estipulada pela Gerência de Infraestrutura Mineração Complexo Mariana foi de reduzir em $40 \%$ o custo por metro perfurado com bucha guia de haste de perfuratriz de grande porte. Ao realizar os testes estatísticos utilizando a carta de controle, verificamos que o CMP, estava em controle estatístico, então utilizamos o limite inferior como nossa meta: $\mathrm{R} \$ 1,83$.

\subsection{Comprovação das causas do problema}

Para definir a causa raiz do problema foi utilizando a metodologia dos testes dos "5 por quês", sendo que, a pergunta inicial do problema.

Por que o custo por metro perfurado é elevado?

Devido ao elevado número de substituição de bucha guia.

Por quê?

A bucha guia da haste de perfuratriz apresenta desgaste na parte interna, sendo necessário o descarte da mesma.

Por quê?

A bucha guia é confeccionada em aço maciço em um único corpo.

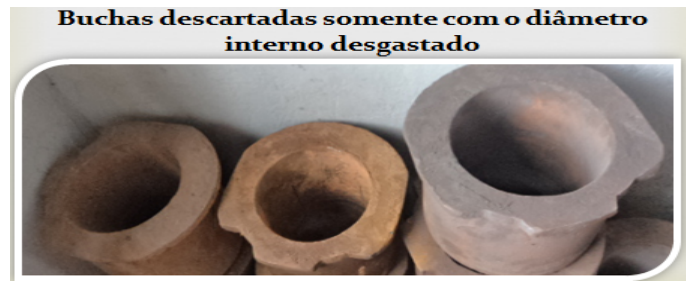

Imagem 8 - Buchas descartadas com diâmetro externo intacto 


\subsection{Solução do problema}

\subsubsection{Brainstorming possíveis soluções}

O grupo realizou um brainstorming onde foram levantadas possíveis soluções.

- Trocar o fornecedor de bucha guia;

- Fabricar a própria bucha guia;

- Desenvolver um novo modelo da bucha guia;

- Fazer a atividade sem a bucha guia.

\subsubsection{Análise de viabilidade de solução}

Através da matriz de viabilidade o grupo avaliou as possíveis soluções com base nos critérios de segurança, custo, aplicabilidade e técnico.

Sendo que, a solução que atendeu todos os requisitos foi desenvolver um novo modelo da bucha guia.

Tabela 4 - Matriz de viabilidade

\begin{tabular}{|c|c|c|c|c|c|}
\hline \multicolumn{6}{|c|}{ MATRIZ DE VIABILIDADE } \\
\hline Solução & Segurança & Custo & Aplicabilidade & Técnico & Justificativa \\
\hline Trocar de fornecedor & x & $x$ & $x$ & $x$ & Não há garantia de melhoria do custo \\
\hline $\begin{array}{l}\text { Fabricação própria da } \\
\text { bucha guia }\end{array}$ & $x$ & $\checkmark$ & $x$ & $x$ & $\begin{array}{l}\text { A empresa não tem know how para } \\
\text { fabricaçăo da bucha guia }\end{array}$ \\
\hline $\begin{array}{l}\text { Desenvolver um novo } \\
\text { modelo da bucha guia; }\end{array}$ & $\sqrt{ }$ & $\sqrt{ }$ & $\sqrt{ }$ & $\sqrt{\square}$ & $\begin{array}{l}\text { A bucha tem duas extremidades, na } \\
\text { qual a parte interna é a que mais se } \\
\text { desgasta. } \\
\text { Com isso, toda vez que a bucha é } \\
\text { descartada a parte externa permanece } \\
\text { intacta. }\end{array}$ \\
\hline
\end{tabular}

\subsubsection{Etapas da solução}

Para desenvolver um novo modelo de bucha guia de hastes, foram levantados alguns possíveis modelos e utilizando o "FMEA" verificou se que o problema da bucha guia de haste era apenas na parte interna da peça, onde ocorre o atrito entre bucha e haste, com isso o melhor método de fabricação do novo modelo da bucha guia de haste era fazer a divisão da bucha, separando a bucha em duas partes, interna e externa, essas peças foram denominadas de refil e camisa, onde somente o refil apresenta desgaste e é substituído.

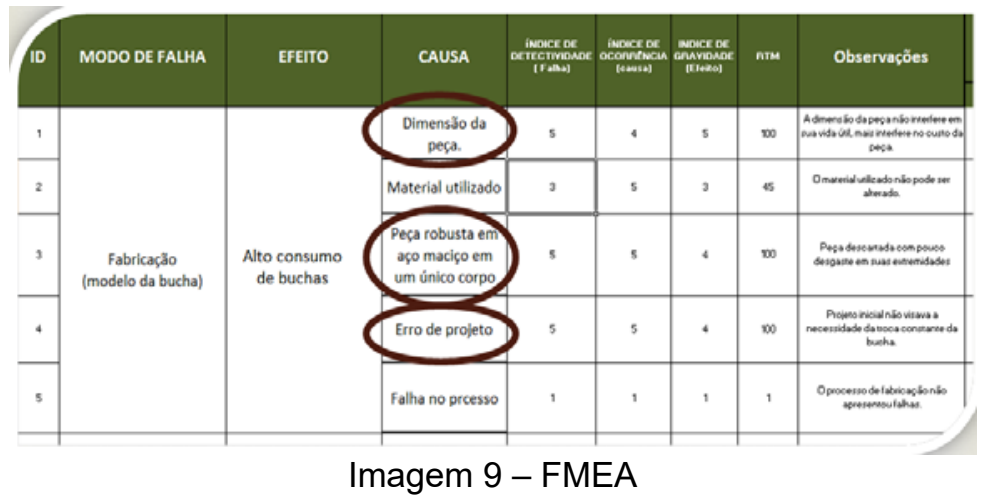

\subsubsection{Plano de ação}

Através da ferramenta $5 \mathrm{~W} 2 \mathrm{H}$ o grupo elaborou o plano de ação para desenvolver um novo modelo de bucha guia de hastes para as perfuratrizes de grande porte. 
2.5.4.1. Desenvolver croqui da nova bucha por meio de software.

\subsubsection{2.}

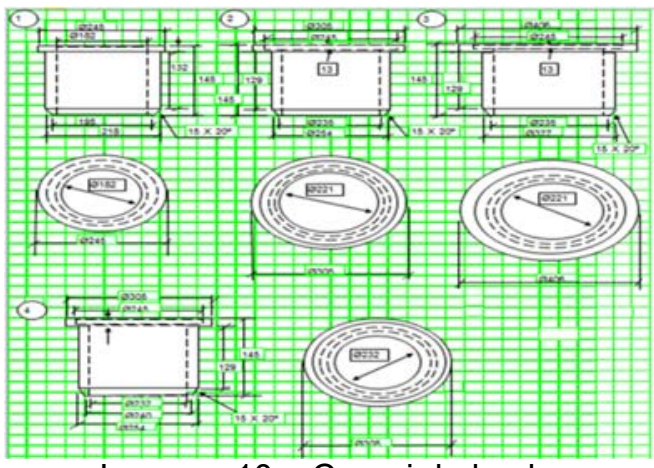

Imagem 10 - Croqui da bucha

2.5.4.3. Solicitar aprovação da engenharia e contratar empresa terceirizada para desenvolver as novas buchas.

2.5.4.4. Testar buchas.

Bucha Guia da Haste
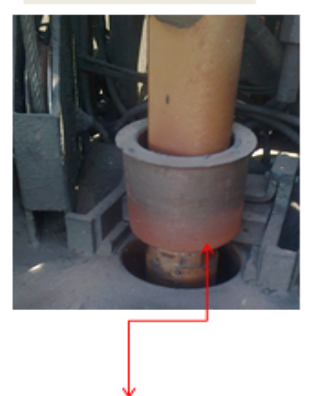

Todas buchas do modelo antigo com fim de vida, serão reutilizada como haste da mesa
Bucha para serem aproveitadas
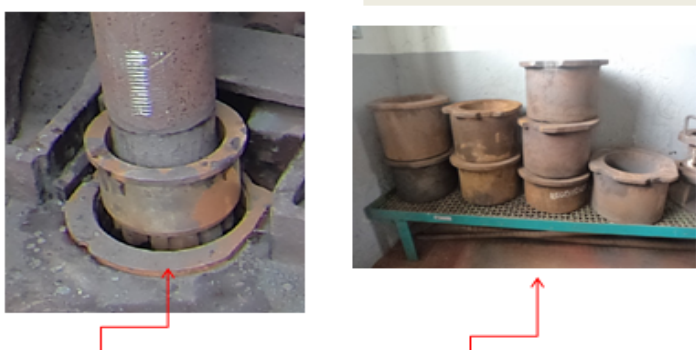

\section{Imagem 11 - Testes do novo modelo da bucha}

\section{RESULTADOS E DISCUSSÃO}

\subsection{Ganhos do projeto}

\subsubsection{Custo}

Ao realizar a substituição do modelo da bucha guia de hastes foi verificado que houve uma redução significativa no custo por metro perfurado devido ao valor unitário da peça (VLU). O valor unitário para aquisição era de $\mathrm{R} \$ 23.000,00$ hoje é de apenas $R \$ 900,00$.

A bucha guia da haste sofreu essa redução devido ao novo método de fabricação, ao dividir a bucha guia da haste em duas partes o diâmetro interno da peça a ser fabricada passou de $78,5 \mathrm{~mm}$ para duas peças, sendo que, uma peça (camisa) tem $19 \mathrm{~mm}$ e a outra (refil) tem $23 \mathrm{~mm}$ e os encaixes agora são feitos através de flanges, por isso, o novo método de fabricação passa ser um processo de fundição simples devido à espessura da peça e como a camisa não sofre nenhum atrito no momento de rotação, só é necessário realizar a troca do refil. 


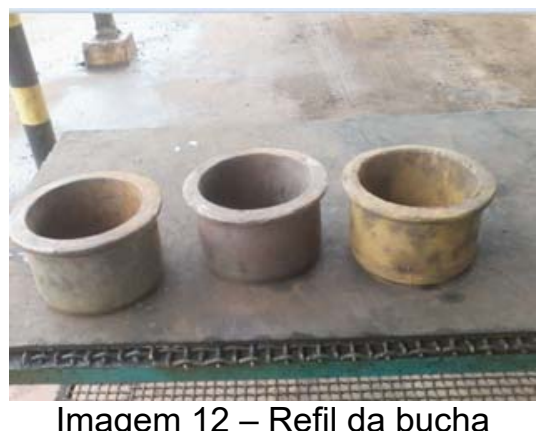

Imagem 12 - Refil da bucha

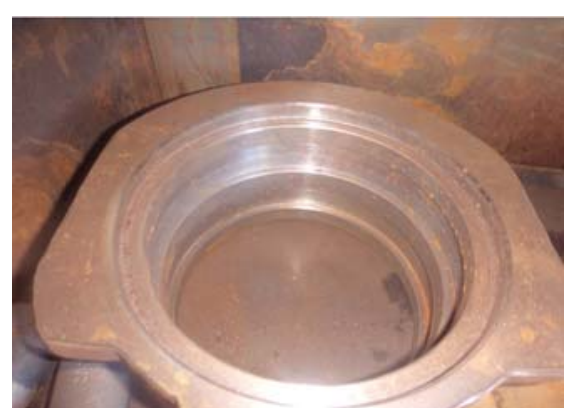

Imagem 13 - Camisa da bucha

O novo modelo da bucha guia da haste sofreu uma redução no valor unitário de $96 \%$ em relação ao ano de 2014 e também teve um aumento na vida útil da peça em $30 \%$ no mesmo período do ano anterior. Com isso, o CMP reduziu para $\mathrm{R} \$ 0,09$ redução de $98 \%$.

Em 2014: CMP $=$ VLU/ VIU:. CMP $=\mathrm{R} \$ 23.000,00 / 7430$ metros $=3,09 \mathrm{R} \$ /$ metro. $\mathrm{Em}$ 2015: CMP = VLU/ VIU:. CMP $=\mathrm{R} \$ 900,00 / 9380$ metros $=0,09 \mathrm{R} \$$ /metro.

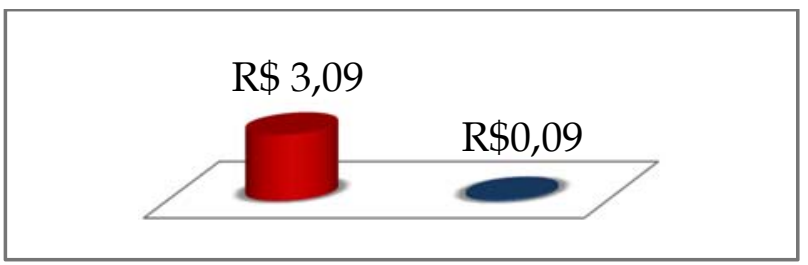

Imagem 14 - Gráfico com custos por metro

Em 2014 foram perfurados $282.558,8$ metros com um CMP de $\mathrm{R} \$ 3,09$, que gerou um gasto de $\mathrm{R} \$ 873.106,69$.

No primeiro semestre 2015 foram perfurados 204.907,11 metros com um CMP de $R \$ 0,09$, que gerou um gasto de $R \$ 18.441,64$.

A redução com buchas guia de haste no primeiro trimestre foi de quase $98 \%$, que gerou um ganho real de $\mathrm{R} \$ 854665,05$, com um potencial de ganho na mesma proporção no segundo semestre.

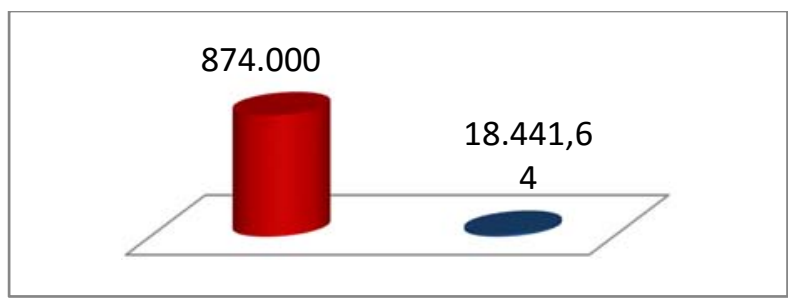

Imagem 15 - Gráfico com custos por período

\subsubsection{Atendimento}

O tempo médio de troca da bucha reduziu de 17 para 7 minutos uma redução de $59 \%$.

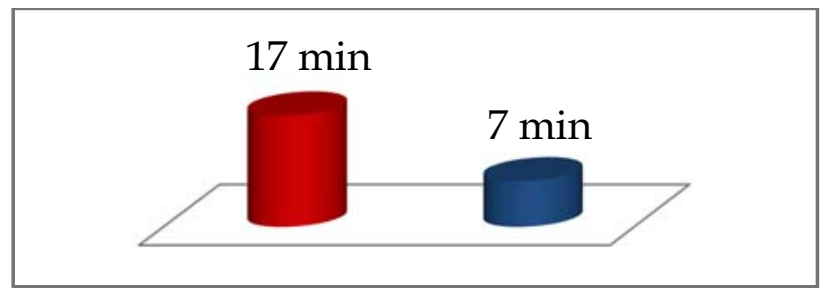

Imagem 16 - Gráfico de tempo médio de troca depois da implantação 


\subsubsection{Segurança}

Todos os riscos relacionados a segurança e ergonomia foram eliminados devido a redução no peso da peça a ser trocada (refil). O peso da bucha foi reduzido de $54 \mathrm{~kg}$ para $23 \mathrm{~kg}$, sendo que somente o refil é trocado e ele pesa apenas $9 \mathrm{~kg}$

\subsubsection{Meio ambiente}

Além de reduzir o peso da bucha guia de haste (refil) a serem descartadas, todas as buchas do modelo antigo foram utilizadas como camisa de mesa para o novo modelo da bucha. O que reduziu em $90 \%$ a geração de resíduo metálico.

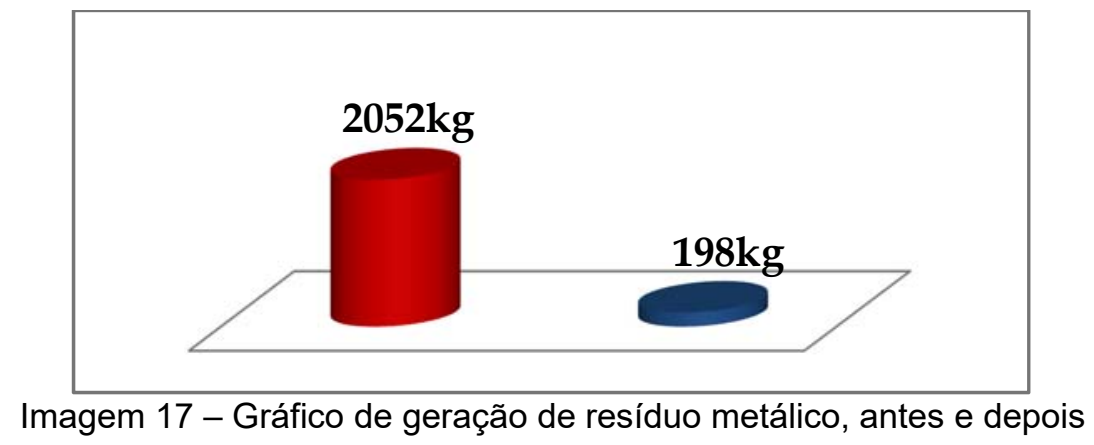

\section{CONCLUSÃO}

O projeto de redução de custo com materiais de desgaste de perfuração, além dos ganhos econômicos, também apresentou ganhos adicionais em redução no tempo de troca da bucha guia, redução no esforço físico ao realizar a troca da bucha, eliminou o risco de pensamento e esmagamento de membros superiores e redução de sucata ferrosa para o meio ambiente.

Esse projeto é aplicável em qualquer processo de mineração que utiliza perfuratrizes de grande porte, sendo que, essa economia com bucha guia de haste será ascendente ao longo dos anos.

\section{Agradecimentos}

Agradecemos primeiramente a Deus pela oportunidade de estarmos aqui, e a essa equipe maravilhosa elencada abaixo:

Péricles Luiz, Luiz Antônio, Juliano Reis, Francisco de Assis, Edson Avelino, Juçara Soares, Marcio Borba.

A equipe de desmonte do Complexo Mariana pelo apoio e pela hombridade.

\section{REFERÊNCIAS}

1 FALCONI, V. Gerenciamento pelas Diretrizes. 2 ed. Belo Horizonte: QFCO, 1996.

2 DEMING, William Edward. Qualidade: a revolução da administração. Rio de Janeiro: Marques-Saraiva, 1990. 